\title{
Cardiac surgery relative to population: pattern of cardiac surgery in South Australia, 1949-75'
}

\author{
H. D. SUTHERLAND, D. R. CRADDOCK, J. L. WADDY, AND G. R. NUNN \\ From the Cardio-Thoracic Surgical Unit, Royal Adelaide Hospital, Adelaide, South Australia
}

Sutherland, H. D., Craddock, D. R., Waddy, J. L., and Nunn, G. R. (1977). Thorax, 32, 570-577. Cardiac surgery relative to population: the pattern of cardiac surgery in South

Australia, 1949-75. The total work load of the sole cardiac surgery unit in South Australia has been analysed by means of a computer-based data retrieval system. The review covers the period 1949-75 inclusive. This study analyses the case-loads year by year, in total, and in different diagnostic categories, and has allowed conclusions to be drawn about surgical needs relative to population figures. From these figures future trends in requirements for cardiac surgical facilities have been deduced.

There are many lessons to be learnt by maintaining an easily recoverable set of data for all the surgery performed in any cardiac surgery unit. This type of analysis makes it possible to maintain surveillance of demands on resources and of the results of the surgery performed.

Because of the structure and situation of the community of South Australia and the fact that it is served by a single open heart unit, the pattern of this series may truly represent the optimum cardiac surgery case-load for any modern westernised community of comparable size.

A computer-based data retrieval system has been designed to store information on all the cardiac surgery performed in South Australia from the year 1949 onwards. The system was developed in 1962 , during which year the 600 operations performed before that time were analysed retrospectively from hospital records, hospital operating lists, and the other medical record data available. Since 1962 the processing has been done while the patient is in hospital and then completed at the time of discharge. Provision is made in the system for follow-up recording but it has not been used in this study.

This analysis uses the data for the years 1949 to 1975 inclusive and its purpose has been to study the cardiac surgery caseloads in South Australia over that period. Certain inferences are drawn from it, particularly about surgical needs relative to population figures and possible requirements in the future.

The population of South Australia was 695618 in 1949 and had increased in approximately linear fashion to 1241700 by December 1975. At the

'Presented to the Society of Thoracic and Cardiovascular Surgeons of Great Britain and Ireland 23-24 September 1976. last census in $1971,70 \%$ of the population were living within 25 miles of the centre of Adelaide. There were six towns with a population of more than 10000 , as indicated on the map (Fig. 1). The combined urban population in the State was $78 \%$ of the total. It can also be seen from the map that this $78 \%$ of the population was deployed

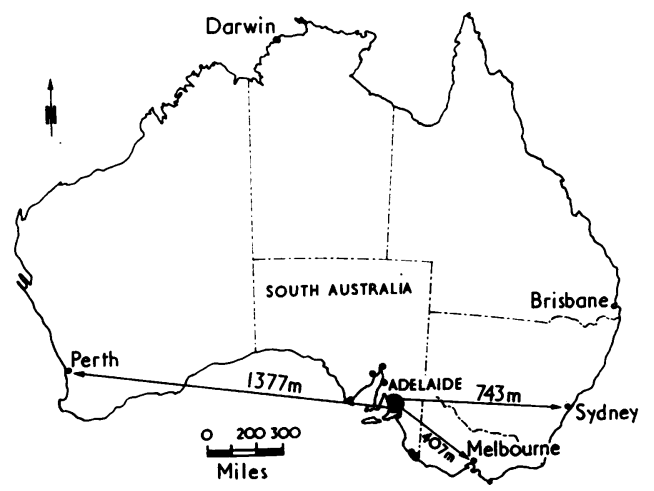

Fig. 1 Showing the area of South Australia, the position of Adelaide, and the six towns with populations greater than 10000. 
centrally in relation to Adelaide. The good highways, efficient internal airlines, and the Royal Flying Doctor system combine to give the remaining $22 \%$ ready communication with the major hospitals in Adelaide. As a consequence, the whole population of the State has ready access to medical care at all levels, including the Cardiac Surgery Unit at the Royal Adelaide Hospital.

Late in 1958 the decision was taken to develop an open-heart surgical service for South Australia and, after a period of planning and team training, this began at the end of 1960 in the Royal Adelaide Hospital (the teaching hospital associated with the University of Adelaide). Over the last 10 years cardiac diagnostic laboratories have been developed in three other Adelaide hospitals but the open-heart unit at the Royal Adelaide Hospital, as a matter of government policy, has remained the only major cardiac surgery service for the State. Except for a small number of closed cardiac operations performed at the Adelaide Children's Hospital, all the cardiac surgery, both open and closed, is now performed in this unit.

The centralised medical policy, the centralised population distribution, and the large distances between Adelaide and cardiac surgery facilities in other capital cities combine to give this study several unique features. Furthermore, it spans the period from 1949, when cardiac surgery in the modern sense was just beginning, until 1975, by which time enormous developments had occurred.

\section{Clinical material}

From 1949 until the end of 1975, 4041 cardiac operations were performed in South Australia (Table 1). There were 1671 operations for congenital cardiac abnormalities, 2100 for acquired cardiac lesions, and 270 pacemaker insertions. These totals include operations performed by both closed- and open-heart techniques. The operative and hospital mortality shown in the table conform to accepted standards.

In this period 2200 open-heart procedures were performed, of which $60 \%$ were for acquired diseases and $40 \%$ for congenital conditions (Table 2 ). The total number of all cardiac procedures per-

Table 1 Total cardiac surgical experience in South Australia, January 1949 to December 1975

\begin{tabular}{lll}
\hline Operation for: & No. & $\%$ Mortality \\
\hline Congenital condition & 1671 & 4.9 \\
Acquired lesions & 2100 & 5.47 \\
All cardiac conditions & 4041 & 4.92 \\
\hline
\end{tabular}

Table 2 Total open-heart surgical operations 1960-75

\begin{tabular}{lrl}
\hline Operation for: & No. & $\%$ Deaths \\
\hline Congenital condition & 894 & $4 \cdot 47$ \\
Acquired lesions & 1306 & $6 \cdot 59$ \\
Total & 2200 & $5 \cdot 72$ \\
\hline
\end{tabular}

formed in each year has increased progressively (Fig. 2A). The graph demonstrates a number of other features. In the years 1961 to 1963 there was a predictable increase because of the existing pool of congenital heart conditions awaiting the advent of open-heart surgery (eg, tetralogy of Fallot, atrial septal defect, ventricular septal defect). In 1963 a significant but temporary increase resulted from the introduction of valve replacement surgery when a second pool of cases had to be treated before the curve resumed its previous slope. In 1970 an almost exponential increase began owing to the large number of operations being performed for coronary artery disease and an increase in the number of pacemaker insertions.

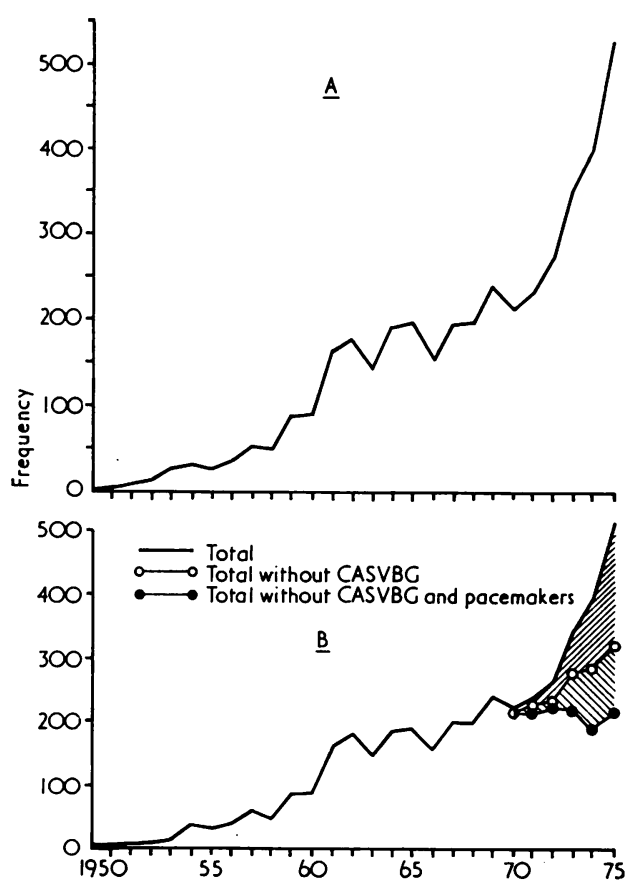

Fig. 2 (A) Total cardiac operations plotted annually. (B) Annual cardiac operations 1949-75 showing the impact of coronary artery surgery and pacemaker insertions after 1970. $C A S V B G=$ coronary artery saphenous vein bypass grafts. 
This is better demonstrated by plotting the curve without revascularisation procedures and pacemaker operations (Fig. 2B) when it can be seen that, apart from these two conditions, the frequency of cardiac surgery operations in South Australia would have remained remarkably constant and continued the trend of the previous 15 years.

A complete open-heart programme makes a considerable demand on community resources in terms of both finance and personnel. When openheart surgery is readily available, it may be required for up to $80 \%$ of all the cardiac operations performed. After the pool of congenital cases had been dealt with in the years 1961 and 1962 (Fig. 3) the number of operations, both open and closed, for congenital lesions remained remarkably constant. From 1963 the number of operations for both acquired and congenital conditions remained almost equal until the year 1970 (Fig. 4) when the progressive increase in the number of cases requiring coronary artery grafting caused a rapid rise in the curve for acquired diseases. Open-heart operations for congenital conditions represented

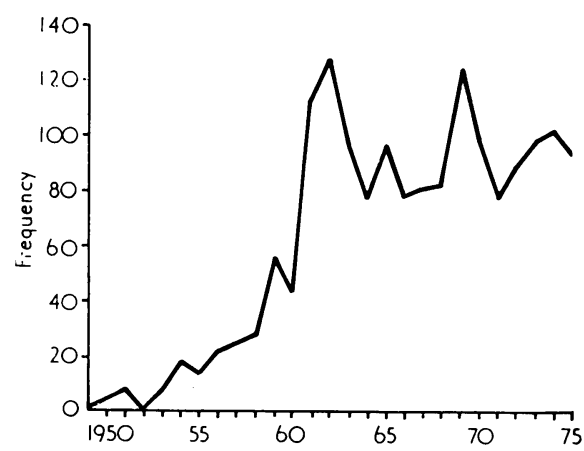

Fig. 3 Congenital cardiac operations (open and closed) plotted annually.

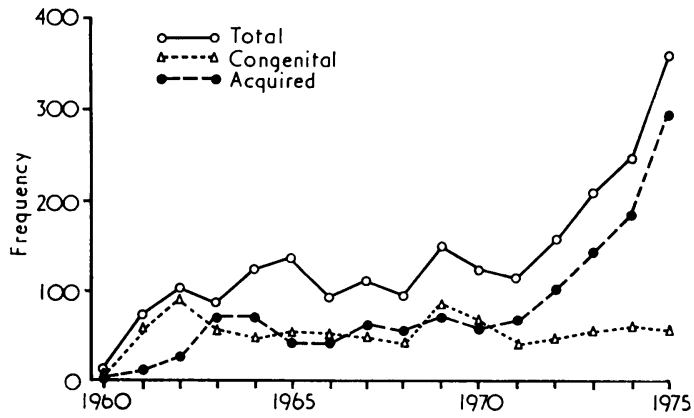

Fig. 4 Open-heart operations plotted annually with separation into congenital and acquired categories. only $20 \%$ of the total open-heart programme for the State by the end of 1975 .

Table 3 shows the total number of operations performed for cardiac disease in Australia as reported in the annual returns to the National Heart Foundation of Australia. This clearly demonstrates that congenital heart surgery remained remarkably constant in the five-year period 1970-74, but during the same period of time the number of operations performed for acquired heart disease virtually doubled.

Table 3 Annual figures for all cardiac surgery performed in A ustralia, 1970-74 (from the National Heart Foundation of Australia)

\begin{tabular}{lll}
\hline & \multicolumn{2}{l}{ Cardiac lesion } \\
\cline { 2 - 3 } Year & Congenital & Acquired \\
\hline 1970 & 938 & 1329 \\
1971 & 966 & 1628 \\
1972 & 988 & 1885 \\
1973 & 1058 & 2217 \\
1974 & 983 & 2596 \\
\hline
\end{tabular}

\section{Surgical procedures}

FOR ACQUIRED DISEASE

During the period 1949-75 (Table 4) $755 \stackrel{2}{\vec{F}}$ patients had valve replacements out of a total of $\frac{3}{3}$ 1306 open operations for all acquired disease. The number of aortic and mitral valve replacements per year remained almost equal throughout. The hospital mortality of $7.5 \%$ for aortic valve replacement, $4.8 \%$ for mitral valve replacement, and $\underset{\times}{\simeq}$ $12.5 \%$ for multiple valve replacement conforms to $\dot{0}$ accepted standards, particularly since these figures represent the total experience from the first valve $ᄋ$ replacement operation performed in the unit in 1963. When the annual frequency of valve re- 윽 placements is plotted (Figs. 5 and 6) there is some annual variation, but the demand for valve replacement surgery has remained relatively con- $N$ stant since 1963. The small mean annual increase runs approximately parallel with the population $N$ growth curve for South Australia over the same period.

Table 4 Prosthetic valve replacements performed in South A ustralia after the first case in 1963

\begin{tabular}{lcc|}
\hline Valve replacement & No. & $\%$ Mortality \\
\hline Aortic & 349 & $7 \cdot 47$ \\
Mitral & 336 & $4 \cdot 76$ \\
Multiple & 80 & $12 \cdot 5$ \\
\hline
\end{tabular}




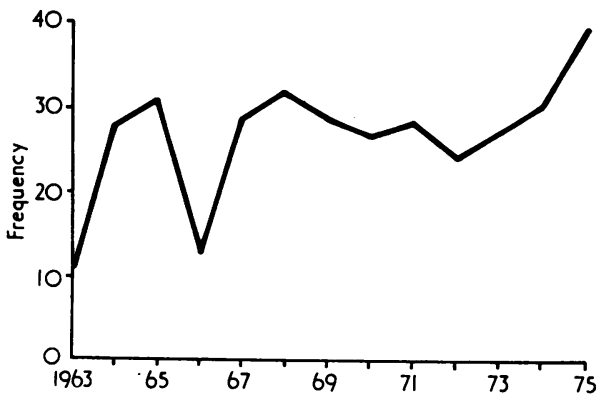

Fig. 5 Aortic valve replacements plotted annually.

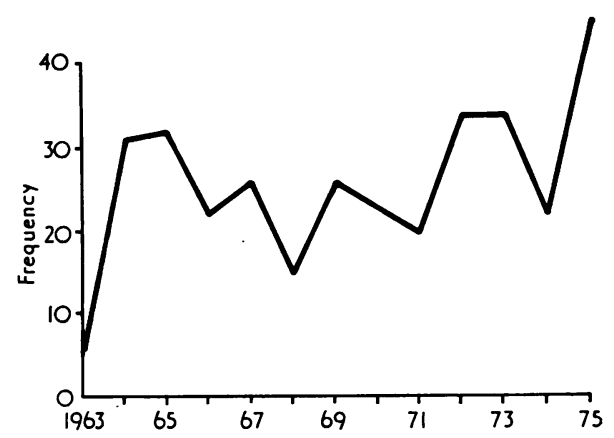

Fig. 6 Mitral valve replacements plotted annually.

The demand for revascularisation procedures for coronary artery disease presents a very different picture, and the experience in South Australia parallels that in most North American centres. The number of operations from the first case in 1970 until 1975 (with annual mortality figures) is shown in Table 5. It reveals that the demand for coronary artery surgery has almost doubled the whole open-heart programme for South Australia over a period of three years, which has thrown a very considerable load on the resources of the cardiac surgery unit.

Table 5. Surgery for coronary artery disease: revascularisation by saphenous vein bypass* listed annually with mortality figures

\begin{tabular}{lll}
\hline Year & Total no. of cases & $\%$ Mortality \\
\hline 1970 & 1 & 0 \\
-1971 & 16 & 0 \\
1972 & 39 & $2 \cdot 56$ \\
1973 & 76 & 3.9 \\
1974 & 109 & $5 \cdot 5$ \\
1975 & 193 & $2 \cdot 6$ \\
& Average & $3 \cdot 45$ \\
\hline
\end{tabular}

* Other associated procedures such as valve replacement and left ventricular aneurysm resection are included.
In the fourth year of the coronary artery programme (1974) the waiting list of patients for elective open-heart surgery had risen from 40 to 110. The latter represented a waiting time of about 13 weeks for surgery. By stepping up the openheart programme to 10 cases a week and appointing a third cardiac surgeon we had reduced the waiting list by December 1975 to 30 cases.

Figures recently available show that the total number of revascularisation operations in 1976 had risen to 260 , which represents a reduction in the rate of increase. The combination of a reduction in the number of cases awaiting surgery and a lowered rate of increase in operations could indicate that the number of cases requiring revascularisation surgery in South Australia may be reaching a plateau.

\section{FOR CONGENITAL DISEASE}

Over the whole period of this review (Fig. 3) there have been 1671 operations performed for congenital heart disease. Eleven per cent of the patients were under the age of 1 year at the time of surgery. Figure 3 shows a number of welldefined peaks. In 1959 the small rise was due to the introduction of surface hypothermia for treating atrial septal defects. In 1961 and 1962 the steep rise was due to the introduction of open-heart techniques for congenital heart surgery, resulting in a large number of cases suddenly presenting for surgical correction. The peak in 1970 is spurious as far as South Australia is concerned, because this represents a number of congenital conditions which were accepted for surgery in the South Australian unit from another State where openheart surgery was temporarily discontinued.

\section{FOR SPECIFIC CONGENITAL ABNORMALITIES}

The frequency of operations over the whole period for some specific congenital abnormalities is demonstrated in Figs. 7 and 8 . The numbers shown are surgically orientated and not related to the total incidence in the community. Figure 7 shows in graphic form the incidence and operative mortality of the commonest single lesions for which surgery is performed.

In Fig. 8 those cases where the lesion is a part of a more complex situation are included. The mortality as expected is higher for each condition.

Tetralogy of Fallot, being a complex lesion in itself, is omitted from Figure 8. There were 219 operations for the tetralogy of Fallot. Of these, 156 were total corrections on cardiopulmonary bypass with a mortality of $7 \cdot 7 \%$, and 63 were palliative shunt procedures. Since 1960, when openheart techniques became available, over $90 \%$ of 


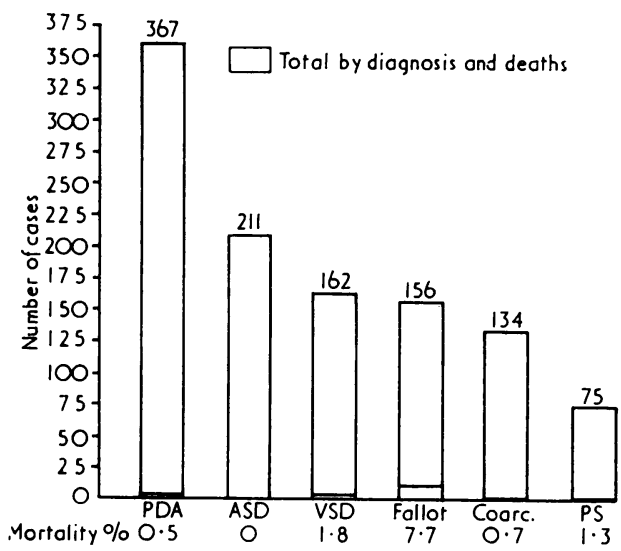

Fig. 7 The commonest congenital abnormalities when occurring as a single lesion. Mortality figures listed below.

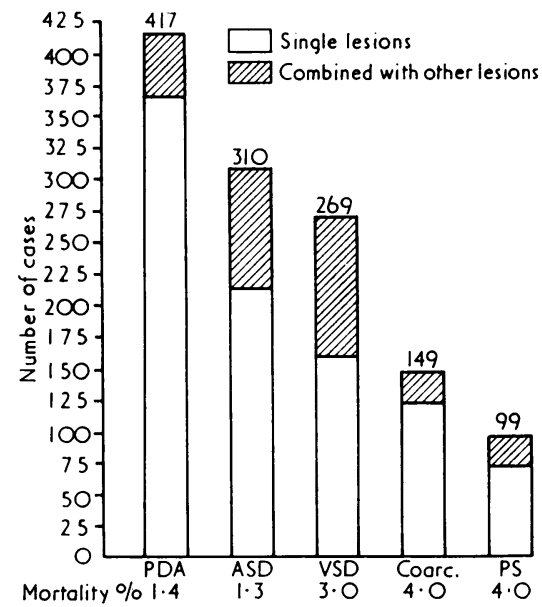

Fig. 8 The commonest congenital abnormalities when occurring with one or more other cardiac abnormalities showing operative mortality.

the shunts have been performed before the age of 2 years. The mortality for the whole series of 63 shunted cases (Blalock, Potts, Waterston, and Cooley techniques have been used at different times) has been $3.2 \%$.

There were 103 operations for uncomplicated coarctation of the aorta in all age groups, with only one death. In 46 cases the operation for coarctation was part of a more complex abnormality. In this group there were five deaths, a mortality of $10.9 \%$. Of the patients operated on for coarctation, 23 were under the age of 1 year at the time of surgery and this subgroup accounted for all six deaths, five of them occurring in patients with multiple and often irremediable cardiac abnormalities. We have analysed the figures for congenital heart surgery in this way because the risk $\frac{\bar{\sigma}}{\vec{D}}$

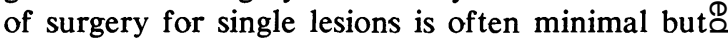
the risk increases significantly if the lesion being treated is a part of a more complex problem.

\section{AT LESS THAN 1 YEAR OF AGE}

Figure 9 shows the birth rate in South Australia over the period of the review and the actual $\vec{x}$ number of births per year. Even though there hasw been a significant decrease in the birth rate from $r$ 1950 to 1973, the actual number of births steadilyor increased until the year 1971 with the overallo population increase. Since 1971 there has been a음 reduced population increase from births but some increase due to immigration. These factors must influence the number of congenital cardiac opera- ${ }_{0}^{\circ}$ tions performed in the neonatal age group (ie, $\Phi$ operations performed at less than 1 year of age). $\vec{\varphi}$ The decrease in operations performed in this age 9 group from a maximum of 18 in 1966 (Fig. 9). probably represents increasing conservatism after a period of some enthusiasm for full correction in preference to staged procedures. The change in approach was the result of experience during theo first six years of open-heart surgery.

The 180 operations performed in children under $\overrightarrow{\vec{O}}$ the age of 1 year at the time of operation are 3 analysed in further detail in Table 6 . In Table $7 \mathcal{\partial}$ the operations at less than 1 year of age are?
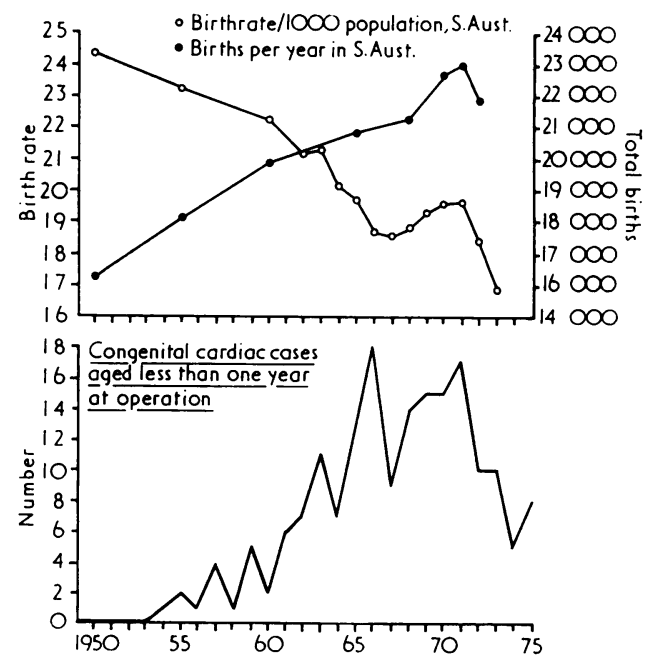

Fig. 9 Birth rate and actual births per year in South A ustralia 1950-73. Congenital cardiac operations performed at less than 1 year plotted annually. 
Table 6 Details by diagnoses and deaths of operations for congenital condition performed on patients aged $<1$ year

\begin{tabular}{llll}
\hline Diagnosis & & Number & $\begin{array}{c}\text { Deaths } \\
(\% \text { mortality })\end{array}$ \\
\hline Patent ductus & Simple & 44 & $2(4 \cdot 44)$ \\
arteriosus & Complicated & 12 & 3 \\
Fallot & Total & 56 & $5(8 \cdot 9)$ \\
& Shunts & 26 & $2(7 \cdot 6)$ \\
Definitive & 1 & 0 \\
Coarctation & Repair & 23 & 6 \\
Transposition & Palliative & 17 & 11 \\
Ventricular septal & Open & 2 & 2 \\
defect & Palliative & 8 & 3 \\
Pulmonary stenosis & Open & 3 & 1 \\
Total anomalous & & 11 & 4 \\
pulmonary venous & & 6 & 1 \\
drainage & & & \\
Vascular ring & & 5 & 1 \\
Other & & 22 & 10 \\
& Total & 180 & $46(25 \cdot 6)$ \\
\hline
\end{tabular}

Table 7 Total figures for operations (open and closed) performed on patients aged $<1$ year with mortality

\begin{tabular}{lcl}
\hline Operation & $\begin{array}{l}\text { Number } \\
\text { (deaths) }\end{array}$ & $\%$ Mortality \\
\hline Closed & $159(40)$ & $25 \cdot 2$ \\
Open with bypass & $21(6)$ & 28.5 \\
$\quad$ Total & $180(46)$ & $25 \cdot 6$ \\
\hline
\end{tabular}

further divided into closed and open procedures. The overall mortality was $25.6 \%$ and was not significantly different for the two groups.

Expected annual frequency of the commoner conditions

It has been possible from the data available to plot the annual operation frequency for some of the commoner conditions. Figure 10 demonstrates that approximately 20 patients suffering from

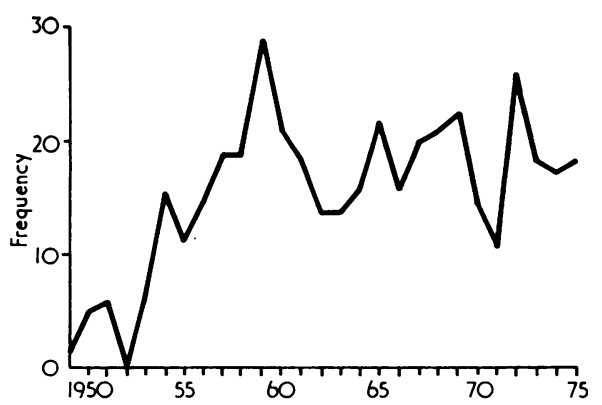

Fig. 10 Patent ductus arteriosus. Operations plotted annually. patent ductus arteriosus have presented for surgery each year and that the incidence has been remarkably constant.

Figure 11 demonstrates the mean age at operation for patent ductus arteriosus. The increasing confidence in surgery for this condition and the policy of operating on patients as soon as the diagnosis has been made, irrespective of age, has brought the mean age at operation down from about 18 to less than 8 years. It can be anticipated that this curve will continue downwards to a mean of less than 4 years because the operation is now rarely performed above that age in this community.

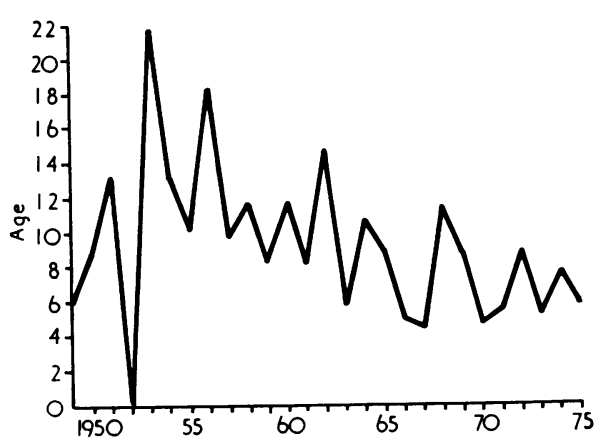

Fig. 11 Patent ductus arteriosus. Mean age at operation plotted annually.

Figure 12 demonstrates the annual frequency of operations for coarctation of the aorta. There are approximately eight operations per year, and now that surgical treatment for the condition has become generally accepted, it seems likely that this rate will continue. As in patent ductus, the mean age at operation for coarctation (Fig. 13) has progressively declined. This was predictable because the age of election for operation was once con-

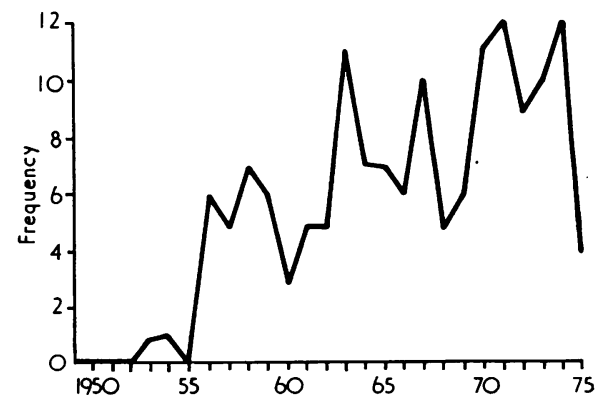

Fig. 12 Coarctation of the aorta. Operations plotted annually. 


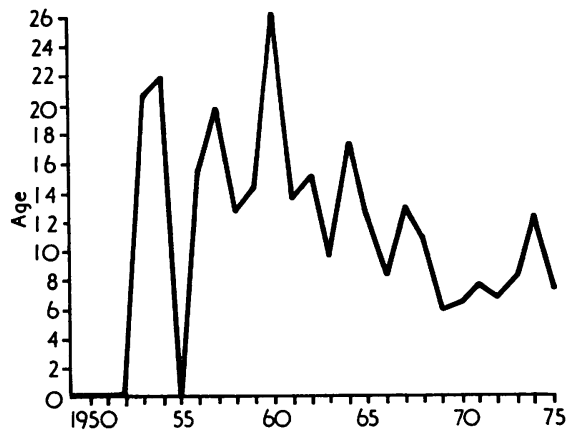

Fig. 13 Coarctation of the aorta. Mean age at operation plotted annually.

sidered to be 10 years, whereas now we operate electively at any age from 2 years upwards. This curve will probably continue its current downward trend until a mean age of approximately 5 years is reached.

The frequency of operation for atrial septal defect (Fig. 14) also follows predictable levels. Following the sharp peak in 1959, when the first operations were performed using surface hypo-

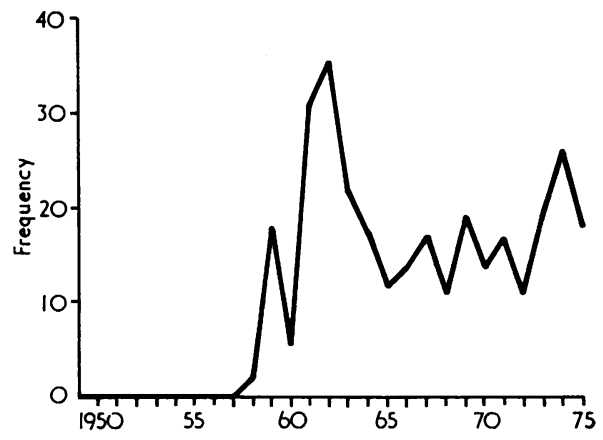

Fig. 14 Atrial septal defect (all types). Operations plotted annually.

thermia, and then the increase in 1961 and 1962 when open-heart techniques first became available, the frequency of closure of atrial septal defect has followed a reasonably stable mean running parallel to the population curve. In contradistinction to patent ductus arteriosus and coarctation of the aorta, the mean age at operation for atrial septal defect (Fig. 15) has remained at approximately 20 years. This is the one congenital lesion which is usually diagnosed and treated in adult life, and the South Australian figures indicate that the present situation is not likely to alter.

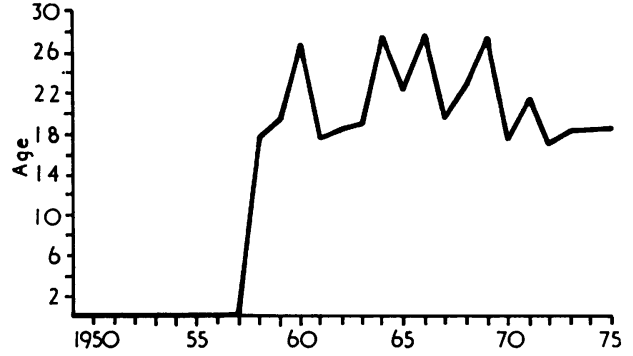

Fig. 15 Atrial septal defect (all types). Mean age at operation plotted annually.

The frequency of surgery for ventricular septalo defect (Fig. 16) shows the same sharp peak follow- ing the introduction of open-heart surgery but, $O$ like the other common congenital abnormalities, $\stackrel{\circ}{\circ}$ the annual mean has now stabilised and again approximately follows the population curve.

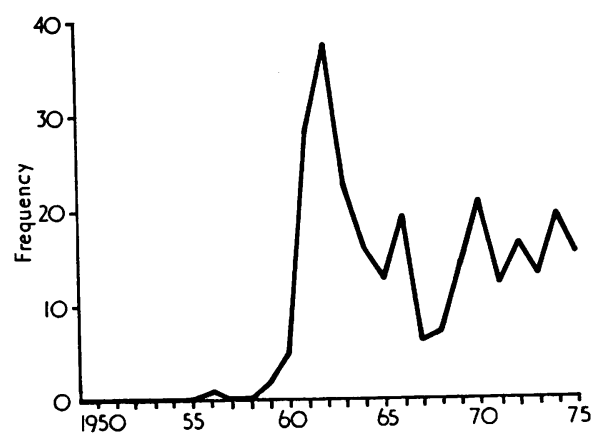

Fig. 16 Ventricular septal defect. Operations plotted annually.

Figure 17 demonstrates the annual frequencys of operations for tetralogy of Fallot. The policy? of this unit has been to perform shunts on patients who need surgical treatment under the age of $2^{\mathrm{N}}$ years. The figures show a fairly constant frequency 0 of patients requiring treatment in these circumstances. The treatment by open operation witho definitive repair was relatively stable in the yearso following the high peak in 1965, which was due to a pool of untreated patients living in South $\stackrel{\text { ( }}{+}$ Australia. The peak in 1969 (as stated earlier) iso spurious as far as South Australia is concernedo because in this year the majority of the patientso came from another State.

Tetralogy of Fallot is a difficult and demandingo condition surgically. In a community of just over 


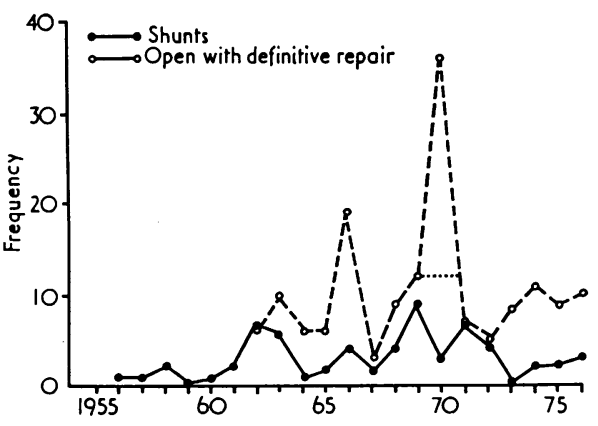

Fig. 17 Tetralogy of Fallot. Operations for full correction on cardiopulmonary bypass and palliative shunt procedures both plotted annually. The peak in 1969 occurred when 23 cases of tetralogy from another State were treated in the South Australia unit. one million people, the total experience in tetralogy of Fallot is restricted to approximately one patient per month. This is probably the minimum requirement for experience in such a condition. It suggests to us that treatment of tetralogy of Fallot should be concentrated in centres for paediatric and neonatal cardiac surgery. The operation should not be performed as an occasional event in units largely devoted to adult cardiac surgery.

Requests for reprints to: H. D. Sutherland, FRCS, Cardiothoracic Surgical Unit, Royal Adelaide Hospital, Adelaide, South Australia. 